\title{
Diamela Eltit: la noción de periodismo tétrico, ideología y discurso en la prensa (neo) liberal chilena*
}

\section{Diamela Eltit: the Notion of Dismal Journalism, Ideology and Discourse in the Chilean (neo)liberal Press}

\begin{abstract}
Resumen
Este artículo analiza la historicidad del concepto de "periodismo tétrico", formulado por la escritora Diamela Eltit, para designar un conjunto de prácticas comunicativas que componen el discurso ideológico de la prensa liberal chilena. Las reflexiones de Diamela Eltit sobre el accionar del sistema de medios en Chile, se insertan en una tradición de estudios teóricos sobre la comunicación, iniciada a fines de la década del 60, que identificó las estrategias discursivas para construir la realidad social definida por la amenaza al orden social instituido, despojando de sentido a las demandas sociales. El artefacto conceptual periodismo tétrico, reactualiza el campo semántico del discurso periodístico liberal en la modernidad globalizada. Permite abarcar la emergencia de nuevos géneros periodísticos de representación de la realidad en clave "espectacular", sobre la base de la función alegórica del mito, la violencia simbólica y los efectos de realidad. El periodismo tétrico es una operación discursiva que reproduce en las noticias la desigualdad estructural del sistema, y más aún, fragmenta esta desigualdad en oposiciones binarias que omiten lo ominoso del contexto social en que emergen los sucesos noticiados. De esta manera, provoca una desconexión sintáctica entre el sujeto de la noticia, el relato social que la envuelve y el predicado que la nomina.
\end{abstract}

Palabras claves

Diamela Eltit, periodismo, discurso liberal, espectáculo

* Este artículo fue financiado por el proyecto Conicyt Fondecyt Posdoctoral Nº 3180431. 


\begin{abstract}
This article analyzes the historicity of the concept of dismal journalism, formulated by the writer Diamela Eltit, to designate a set of communicative practices that make up the ideological discourse of the Chilean liberal press. The reflections of Diamela Eltit on the actions of the media system in Chile, are inserted in a tradition of theoretical studies on communication, initiated in the late 60 s, which identified the discursive strategies to build the social reality defined by the threat to the social order instituted, stripping of meaning to social demands. The conceptual artefact, dismal journalism, updates the semantic field of liberal journalistic discourse in globalized modernity. It allows to cover the emergence of new journalistic genres of representation of reality in a "spectacular" key, based on the allegorical function of myth, symbolic violence and the effects of reality. The dismal journalism is a discursive operation that reproduces in the news the structural inequality of the system, and even more, fragments this inequality in binary oppositions that omit the ominous of the social context in which the news events emerge. In this way, it causes a syntactic disconnection between the subject of the news, the social story that surrounds it and the predicate that nominates it.
\end{abstract}

Keywords

Diamela Eltit, journalism, liberal speech, show

En víspera de las elecciones presidenciales de 2017, la cadena televisiva CNN Chile, emitió un programa de foro ciudadano y debate político, denominado "Aquí está Chile", que pasó a la historia del periodismo nacional como el paradigma de lo que la pensadora Diamela Eltit denominó conceptualmente "espectáculo periodístico tétrico".

Este programa pretendía ser una adaptación de los foros de los ayuntamientos, en Estados Unidos, donde los políticos se reúnen a debatir con sus electores. Sin embargo, la versión criolla usó el formato televisivo denominado infoentretenimiento; un género periodístico híbrido que fusiona información y entretención; donde la información es concebida como una mercancía que, para ser comerciada eficientemente, necesita ser revestida de lo que se considere oportuno para ser consumida por una amplia audiencia (Soler y Marzal 84). Aunque la mayoría de los estudios académicos sobre este género abordan casos de la televisión, el nombre designa un estilo periodístico de representación de la realidad

${ }^{1}$ Eltit, "Aquí Está Chile". https://www.youtube.com/watch?v=Fb sUMQ9aNA 
en clave espectacular que puede darse en cualquier medio de comunicación (Berrocal, Redondo y Campos 67).

La edición de "Aquí está Chile" del 7 de junio de 2017, confrontó a la precandidata presidencial del Frente Amplio, Beatriz Sánchez, con el caso "real" del comerciante Pablo Oporto, quien fue presentado como el paradigma del emprendedor ejemplar, fundador de una cadena de locales en una población marginal de Santiago. Su caso era "espectacular", porque había resistido más de cien asaltos y logrado matar a doce delincuentes. Con intenso dramatismo, se transmitió una nota previa de la historia de Oporto, cargada de imágenes impactantes, algunas en blanco y negro captadas por cámaras de seguridad, con primeros planos de orificios de bala, y una secuencia de carga de pistola en un entrenamiento de tiro. El relato periodístico fuera de cámara subrayaba que los asesinatos de Oporto fueron legales ya que la justicia chilena lo había exculpado por las doce muertes ocurridas en legítima defensa.

En el género infoentretenimiento, el periodista tiene un rol coprotagónico; no es un simple mediador de la información, sino que sus comentarios, los recursos narrativos que emplea y su opinión sobre los hechos, incitan la expectación del público (Morales 9). Fue así como la periodista Mónica Rincón, rostro ancla de $\mathrm{CNN}$, acorraló a la candidata con la pregunta acerca de si ella también dispararía a los delincuentes por defender a sus hijos, conminándola a responder sí o no.

Diamela Eltit calificó la pregunta de "sensacionalista", porque se encuadra en una forma de violencia binaria reducida al sí o no, que contiene lo peor de la cultura occidental (Eltit, "Aquí está Chile"). En tales oposiciones como blanco/negro, homogéneo/diverso; simple/reflexivo, hombre/mujer, Derrida demostró que implican una jerarquía en que los segundos términos acaban siendo estigmas o "marcas" (Laclau 49). Eltit también cuestionó la relación periodista/entrevistado en este programa, donde el tono y el ritmo de las preguntas creaban la sensación de que los invitados eran imputados sometidos al interrogatorio de un juicio oral y público: 
el espacio televisivo en este tramo electoral se ha transformado en una especie de teatro de la humillación que, bajo el presupuesto de la información, la veracidad, la neutralidad (que no existe) construyen la figura de la o el periodista bajo la impronta heroica de una superioridad moral que "desnuda" a su entrevistado o entrevistada [...] Más que entrevistas se adopta el formato de un temible interrogatorio. (“Aquí está Chile")

Con la controvertida pregunta, la periodista de CNN no solo traspasó al comerciante su propia credibilidad en forma acrítica, avalando la veracidad de su testimonio, sino que, además, al obligar a la entrevistada a ponerse en el lugar de Oporto, habilitó la tenencia y el uso de armas de fuego como estrategias de legítima defensa en el caso de las madres que por sus hijos disparan a matar.

De esa manera se abrió un escenario melodramático conocido que promueve la abnegación materna hasta llegar al crimen y a la pérdida de lucidez por el peso de las emociones más que estereotipadas inculcadas por la supremacía masculina. [...] Porque "esa" pregunta dirigida hacia una mujer, contenía una maternidad que deja fuera la vida pensante y lúcida de la madre y la suple por la abnegación (del tipo religioso) al hijo al punto de cegarla. ("Aquí está Chile")

Aunque la candidata no respondió la pregunta, señalando que no tendría armas y que buscaría otra forma de defender a sus hijos, los telespectadores recibieron un mensaje saturado de inusitada violencia semántica, o, como señala Diamela Eltit, la audiencia fue perturbada por "un conjunto de signos agudizados hasta el paroxismo" para construir al delincuente como sujeto de exterminio; es decir, como merecedor de la reacción violenta de la ciudadanía hasta provocarle la muerte. 
Eltit criticó duramente las prácticas periodísticas del programa, calificando de "inédito, asombroso y verdaderamente aterrador para la democracia y un real Estado de Derecho" (“Aquí esta Chile”), el discurso ideológico amplificado desde diferentes ángulos para naturalizar la pulsión criminal y el ajusticiamiento ciudadano, como instancias de legítima defensa:

implica un llamado al exterminio de todos los asaltantes por parte de comerciantes y privados. Una real negación de la desigualdad, del reconocido aporte de los niños del Sename estatal como semillero delictual, de un estímulo ante un hecho inaceptable en la televisión abierta como es incentivar la balacera en manos de civiles. (“Aquí está Chile”)

Más aún, la suspicacia de la escritora puso al descubierto lo que ningún periodista de los presentes en el programa fue capaz de advertir: el montaje ficcional construido por Oporto y validado por los medios, para suscitar en los telespectadores una empatía con su construcción de personaje mítico, una especie de alegoría en carne y hueso de la impotencia ciudadana sobrepasada por la delincuencia:

Un sujeto que mató en defensa propia a DOCE asaltantes y que hasta donde se vio en el programa, no había recibido ni una sola herida (ni él ni su familia) por parte de sus cien agresores. Más aun, lucía sus aptitudes paramilitares disparando, a la manera del Far West, en un territorio sin dios ni ley. Personalmente me pareció semejante a un ajusticiador en serie de delincuentes. Pensé que bajo el ropaje de la víctima se escondía, quizás, una forma de placer retorcido [...] un hecho inaceptable en la televisión abierta como es incentivar la balacera en manos de civiles mediante la compasión acrítica a una persona que ha matado en forma tan reiterativa que empuja a la sospecha. (“Aquí está Chile”) 
Las dudas de Diamela Eltit sobre la falsedad de este caso motivaron una investigación de Revista Sábado de El Mercurio, que confirmó que Oporto era un "justiciero imaginario"2. Exactamente lo que Cáceres identifica en el género infoentretenimiento como "protagonistas de acontecimientos mediáticos" (210214); sujetos sin relevancia social elevados a la categoría de estrellas por hechos que no tendrían existencia real si los medios de comunicación no dieran cuenta de ellos. Oporto no había ajusticiado a nadie, tenía antecedentes delictuales de violencia intrafamiliar y de maltrato animal, sin embargo, llevaba múltiples apariciones en los canales y en la prensa escrita, promocionado como símbolo del coraje ciudadano para resistir a la delincuencia.

Por más de 20 años, a través de diversas columnas publicadas en la prensa, la Premio Nacional de Literatura, ha formulado un análisis conceptual sobre el accionar de los medios de comunicación de Chile como superficie de emergencia de un discurso ideológico que contradice la supuesta neutralidad u objetividad en el ejercicio del periodismo. A su juicio, el sistema de medios está al servicio de la expansión del modelo neoliberal instaurado por la dictadura, acrecentando la formidable desigualdad estructural que caracteriza a la sociedad chilena.

El planteo de Eltit se inserta en una línea de estudios teóricos iniciada en nuestro país por los investigadores de la comunicación Armand y Michèle Mattelart, y Mabel Piccini, a fines de los sesenta. Ellos rastrearon la estructura de poder en la información, monopolizada por la elite propietaria de la prensa, detectando la forma en que opera la ideología mediante mecanismos reductores de la realidad para ocultar las fisuras y contradicciones del sistema en los hechos noticiosos (Mattelart, Mattelart y Piccini, Los medios de comunicación).

La definición de ideología considerada en este artículo es la de Teun Van Dijk, teórico de la perspectiva del Análisis Crítico del Discurso, quien elaboró un concepto con un enfoque multidisciplinario que incluye tres dimensiones: cognición (social), sociedad y discurso. Van Dijk señala que las ideologías son

\footnotetext{
${ }^{2}$ Fluxa y Galarce, "El justiciero imaginario".
} 
sistemas de creencias socialmente compartidas por los miembros de una colectividad de actores sociales. Éstas determinan la identidad social de un grupo específico en torno a sus creencias sobre sus modos de vida y de reproducción. Su principal función cognitiva es organizar las representaciones sociales del grupo y operan mediante modelos mentales que conectan la memoria social (semántica) con la memoria personal (episódica) que es lo que finalmente relaciona la ideología con las estructuras del discurso. El discurso tiene una función especial en la implementación y reproducción de la ideología, ya que ésta solo puede manifestarse mediante el uso de la lengua, la comunicación y otras prácticas semióticas. Las ideologías no se miden por su valor de verdad, sino por su efectividad en el manejo del pensamiento y la interacción. No están limitadas a grupos dominantes, aunque pueden funcionar como legitimadoras del abuso de poder y la desigualdad, también pueden ser la base de la resistencia, desafío, disidencia y cambio social; en ese sentido una ideología puede ser racista o feminista. No obstante, cuando hay elites que tienen acceso preferente al discurso público y al control de éste, a través de los medios de comunicación o la educación, cumplen una función especial en formular y reproducir ideologías en el debate público (Ideología 391-397). Dado que la relación entre discurso y poder es crucial en la dominación discursiva, el Análisis Crítico del Discurso se enfoca en los grupos dominantes que crean y mantienen la desigualdad social por medio de las comunicaciones y el uso del lenguaje (Van Dijk, "Discurso y dominación” 8).

El objetivo de este artículo es indagar las capas de sedimentación histórica que preceden al concepto de periodismo tétrico acuñado por Diamela Eltit, determinando su formación discursiva, el alcance de su campo semántico y explorando su potencia como artefacto comunicativo para designar un conjunto de prácticas que componen el repertorio ideológico de la prensa liberal chilena.

La hipótesis planteada es que la noción de periodismo tétrico, propuesta por Eltit, permite poner al descubierto una estrategia ideológica de polaridad social orientada a construir mediáticamente la realidad definida por la amenaza al orden 
establecido, activando un clima de inseguridad creciente, favorable a la expansión del capital y a la naturalización de la desigualdad.

Ello se fundamenta en la existencia de un a priori histórico que se reitera en la materialidad enunciativa de la prensa liberal chilena, configurada en torno a ciertas categorías que operan como condiciones de posibilidad de su ejercicio. Algunas de ellas son: el monopolio de la libertad de expresión como derecho de propiedad privada de los actores del mercado informativo; la confirmación de los estereotipos sociales para el mantenimiento de las jerarquías; el uso de los códigos del espectáculo y la función alegórica del mito en la construcción de las noticias para desactivar amenazas a los privilegios de las elites. Todas estas categorías apuntan a naturalizar la violencia de la desigualdad estructural de los modelos de desarrollo de pre y postdictadura.

Este artículo se divide en tres secciones, en el primer momento, a partir de las reflexiones de Diamela Eltit sobre los medios de comunicación, publicadas en diversas columnas de prensa desde 2005, intentamos delinear las premisas teóricas y el campo semántico que prefigura el concepto de periodismo tétrico. En el segundo momento, revisamos la tradición del discurso ideológico de la prensa liberal chilena, estudiada por diversos teóricos de la comunicación y analistas del discurso, desde 1900 hasta el inicio de la transición chilena. Al comienzo de este periodo posdictatorial, se produjo una inflexión en la amenaza y el miedo como instrumentos de control social, desplazándose desde el espacio subjetivo de "la doctrina de seguridad nacional a la doctrina de seguridad ciudadana" (Ramos y Guzmán). En el tercer momento acotamos la definición de periodismo tétrico, en relación con la hipótesis para concluir con las reflexiones finales.

\section{Primer momento: las columnas periodísticas de Eltit}

En sus observaciones críticas sobre las prácticas de construcción de las noticias en el sistema de medios de Chile, la pensadora Diamela Eltit, ha ido 
estableciendo diversas premisas teóricas que fueron prefigurando la noción que hoy designa con el sintagma adjetival: "periodismo tétrico".

Una primera aproximación al campo semántico del artefacto comunicativo que es objeto de este estudio fue formulada por Eltit en un artículo de 2005 ("La memoria pantalla" 31), donde utiliza el significante "siniestra" para referirse a la estrategia de espectáculo y a la voluntad cómplice de silenciamiento de la industria televisiva chilena destinadas a anular el dramatismo de las imágenes de la caída del gobierno de la Unidad Popular.

En el marco de conmemoración de los 30 años del golpe militar, la fecha aniversario era el puente, el marco emblemático (Stern) para un acto de rememorar que sin embargo operó como pantalla de la intencionalidad de provocar el olvido. La estrategia mediática consistió en producir un copamiento de imágenes que sobresaturó las pantallas televisivas hasta el punto de aniquilar, por exceso, su eficacia como soporte de la memoria de millones de chilenos que vivieron la caída de Allende como una catástrofe social, con su trágica secuela de detenidos, desaparecidos, torturados, y fusilados.

A juicio de Eltit, con meros propósitos de mercado, las imágenes de Allende fueron exhibidas como la secuencia de una carrera turística hacia el pasado, administrada por narraciones visuales basadas en anécdotas y relatos tan generales que permitían ocultar lo verdaderamente importante que era el proyecto político de la Unidad Popular. Para la escritora este "hit mediático", no fue construido para oficializar un tramo de la historia, sino para confirmar el pacto de censura sobre la memoria del segmento temporal conmemorado, con el propósito de lograr "el necesario blanqueo político que va a permitir la implantación de un tema que se desea transitorio" ("La memoria pantalla" 32).

En esa maniobra, Eltit percibió la "extrañeza inquietante" con que Freud define lo siniestro, lo ominoso, lo tétrico, ya antes elaborado por Shelling, como la carga fantasmática que insinúa lo escondido y peligroso; "lo que debía de haber quedado oculto, secreto, pero que se ha manifestado" (Errázuriz 1). Así, la estrategia de "exceso", deviene en desmemoria a consecuencia de la paradoja 
misma de su representación, definida por Enaudeau (9) como un juego simultáneo de opacidad y transparencia: una presencia que finalmente confirma la ausencia. De esta manera, la manipulación de las imágenes de los 30 años del golpe, precisamente por la abundancia de su oferta mercantilizada, en lugar de iluminar lo mostrado, lo eclipsan, lo borran y lo tachan, traicionando su sentido al tornarlo una representación engañosa. ¿Por qué entonces el horizonte de representación de las noticias en lugar de perfilarlas, las desdibuja?

En la perspectiva de Eltit, la concentración monopólica del sistema de medios en la derecha política y económica determina en forma permanente el encuadre de la porción de realidad que visibiliza en sus productos periodísticos. En este marco, los hechos noticiosos validados son aquellas informaciones que encajan con su proyecto político y económico, subordinando el discurso periodístico a la maquinaria de propaganda de su empresa de persuasión ideológica.

La desigualdad económica y social chilena nos habla de una concentración de bienes sin precedentes. [...] posee, entre sus múltiples haberes, numerosos medios de comunicación del país: televisión, radios, periódicos que velan porque esa concentración se mantenga. Los medios producen "efectos de realidad" para capturar no sólo a los auspiciadores sino también a sus lectores o espectadores. Porque los "efectos de realidad" están diseñados para favorecer al capital, para incrementar las ganancias y gratificar a los grandes consorcios de los cuales los medios forman parte. ("Arrate en el debate")

La escritora recoge de la crítica literaria y de Pierre Bourdieu (Sobre la televisión 27-28), el concepto de "efecto de realidad" para definir un atributo de las imágenes utilizado por la prensa televisiva como mecanismo de elaboración social de la realidad. Esta cualidad permite mostrar y a la vez hacer creer en lo que muestra. Por ello, aunque medios como la televisión pretendan reflejar la realidad, acaban convirtiéndose en instrumentos de creación de realidad. 
No es que determinadas situaciones sean reales ni menos verdaderas, sino se genera esa condición mediante la intervención de los poderosos discursos públicos. Los medios de comunicación y sus intereses económicos y corporativos tienen un lugar preponderante para conseguir el éxito de estas construcciones. (“Arrate en el debate”)

Eltit remarca que además existe otro factor que incide en que las audiencias estimen como verdaderas las construcciones del "efecto realidad", se trata de lo que Bourdieu denomina el "poder hipnótico de la dominación" (La dominación masculina 5), que se materializa mediante violencias simbólicas imperceptibles aún para sus víctimas. Éstas no pueden captarlas, ya que se encuentran sometidas al influjo de poderosos discursos sociales que naturalizan la violencia estructural del sistema para mantener el control de la población:

Más allá de las ganancias de los inversionistas, hay que pensar la televisión, diarios y radios, en manos de poderosos privados, no solo como una fuente de ganancias contantes y sonantes (muchas de ellas tienen pérdidas asombrosas), sino especialmente como instrumentos de poder, como una manera de "producir" sujetos dóciles, adictos a la simpleza y al melodrama, como una forma de alienación programada, como una manera de intensificar controles y opciones políticas pactadas por el gran capital. (“Aquí está Chile”)

Ahora bien, Eltit reconoce que, como cualquier espacio social, los medios también "son porosos" y permiten en algunos casos difundir discursos culturales consistentes y coherentes, (“Miguel Serrano”). Sin embargo, asegura que la medida general sigue siendo la concentración mediática, manejada por elites que comparten filiaciones de clase o bien reproducen los supuestos neoliberales imperantes: 
Así, los espacios culturales de los medios de comunicación no pueden sino reflejar mayoritariamente el deseo de resaltar producciones ligadas al éxito (la literatura como empresa) como también integrar de diversos modos y con distintas tecnologías sujetos de "clase" o a aquellos funcionales al proyecto económico en la medida que los medios son propiedad de la derecha política. ("Miguel Serrano”)

Ciertamente, el clasismo es una entre muchas otras manifestaciones de lo que Eltit, siguiendo a Bourdieu (Sobre la televisión 23-24), denomina "violencia simbólica" en la comunicación mediática. La clase social aparece entonces como una categoría básica en la selección de los contenidos periodísticos que se difunden. De hecho, la segmentación de contenidos se ciñe a la escala de estratificación socioeconómica utilizada por el marketing para la captación de avisaje publicitario, clasificando a la audiencia en consumidores AB, C1 A, C1B, C2, C3, D y E 3 . Con esta gradación, las realidades sociales son reducidas a índices formales de consumo y el clasismo se transfiere al discurso periodístico permeando al conjunto de sus productos editoriales:

Un comentarista dominical aseguró que el candidato que yo apoyo (en política yo me comprometo con opciones y no con maridos), Jorge Arrate, parecía un profesor de liceo. Lo señaló con un matiz profundamente

3 La Asociación Nacional de Avisadores (ANDA) y la Asociación de Investigadores de Mercado (AIM), presentaron en 2018 una actualización de la segmentación socioeconómica en Chile. El grupo más alto es el $\mathrm{AB}$, nivel de ingresos promedio mensual $\$ 6.452 .000$, un $99 \%$ son profesionales universitarios, en un tercio de los casos tienen títulos de posgrado. El $89 \%$ tienen ISAPRES, el 92\% cuenta con una tarjeta de crédito bancaria. Asimismo, ocho de cada diez tienen al menos un vehículo y el $89 \%$ posee un plan de telefonía móvil (el 11\% restante ocupa prepago). El grupo $\mathrm{AB}$ representa el 3\% de los hogares del Gran Santiago, y se concentra casi exclusivamente en las comunas del sector nororiente de la capital: Vitacura, Las Condes, Lo Barnechea y Providencia. A este segmento le siguen dos nuevas categorías, denominadas Cla y $\mathrm{C} 1 \mathrm{~b}$. La primera de ellas posee ingresos totales promedio mensuales de $\$ 2.739 .000$, mientras que la segunda llega a $\$ 1.986 .000$. Y si bien ambas tienen características similares (cada una representa el 6\% del país). C2, ingreso promedio mensual \$1. 360 000; C3 899.000, D 562000; E, 324000. Fuente "Nuevos grupos socioeconómicos 2018 AIM Chile" disponible en www.aimchile.cl. 
irónico, clasista y despreciativo hacia los miles de miles de profesores chilenos de enseñanza media de colegios municipalizados de los que yo misma he formado parte. (“Arrate en el debate")

Aquí Eltit alude al elitismo periodístico que también se refleja en mecanismos excluyentes al interior de sus productos editoriales. Por ejemplo, los espacios dominicales se reservan en la televisión a programas de debate político, y en la prensa escrita a las columnas de escogidos analistas políticos, cuyos estilemas son una lingua franca tácita dirigida a la clase política y al lector de nivel social $\mathrm{AB}$ y $\mathrm{C} 1$, que se informa, toma decisiones y adquiere opinión a partir de la lectura de esos textos y, de las emisiones de los programas políticos dominicales. La mayoría de los columnistas influyentes son hombres; algunos de ellos ejercen sin complejos como funcionarios de agencias de lobby y comunicación estratégica; otros son académicos de universidades privadas o empresarios que evalúan la marcha del país según sea o no favorable a "la inversión", es decir, a sus utilidades económicas.

Para el periodista Paul Walder, el espacio de debate político dominical "Tolerancia Cero", grafica el ejercicio del periodismo al servicio del poder para el mantenimiento del statu quo. Walder sostiene que este programa es uno entre muchos productos serializados del sistema de medios que trasladó a la política los códigos del formato reality show:

Espacios de debate político como Tolerancia 0 (en CNN y Chilevisión, ambas cadenas del gigante transnacional Time Warner), por nombrar uno de los ya profusos y serializados productos, buscan establecer nuevas marcas en los mercados comunicacionales. Un estilo, aun sin haber ingresado en la categoría del abierto terror, inaugura la tipología del agravio, la iniquidad, la ignominia. El espectáculo -y vale la pena verloes una nueva versión del ya superado reality, esta vez trasladado a la esfera política. (Walder) 
Justamente en este programa, el senador Manuel José Ossandón, se refirió al conflicto mapuche en la Araucanía, señalando que si era necesario "meter balas, hay que meter balas al que sea terrorista". ${ }^{4}$ Diamela Eltit, criticó en ese espectáculo mediático la difusión de una "pulsión criminal contra el pueblo mapuche" (Eltit, Aquí está Chile"). De ahí que Walder remarca que el programa estuvo muy cerca de cruzar la delgada línea que separa el periodismo del "terrorismo mediático", concepto que abordaremos en el próximo apartado.

Otra manifestación de violencia simbólica, muy frecuente en el conjunto de medios, es la paradoja definida por Bourdieu (Sobre la televisión 23-24) como “ocultar mostrando", o sea, presentar las noticias de tal forma en que se invisibilizan aspectos pertinentes que debería conocer el ciudadano para ejercer sus derechos democráticos. Este problema fue analizado por Eltit en una columna de $2016^{5}$, donde critica la cobertura periodística sobre la corrupción en la clase política, un tema que, pese a ser fundamental para la democracia, fue tratada en los medios en forma insubstancial:

Un espacio tóxico, superficial, plagado de informaciones infractoras que no consiguen fijarse porque se suma una y otra, una sobre otra, hasta que lo heterogéneo se vuelve homogéneo y lo excepcional se convierte en norma. Entonces todo es igual, lo mismo. La ecuación política, evasión, cohecho consiguió convertirse en una suerte de farándula noticiosa estimulada por los conjuntos de los medios de comunicación que, más allá de excepciones, parecen incapaces de detenerse para realizar análisis detallados [...] marcan pautas que nunca terminan su guión y sirven solamente para producir un cierto suspenso y amplificar el caos. (Eltit, "Bachelet Qué Pasa")

\footnotetext{
${ }^{4}$ Las declaraciones de Ossandón fueron reproducidas en Radio Cooperativa, el mismo domingo de la transmisión.

5 Eltit, “Bachelet, Qué Pasa y el 'caso’ del matrimonio Dávalos-Compagnon: Hacer noticia”.
} 
Las violencias simbólicas y los "efectos de realidad" permiten a los medios dirigir su impacto a la permanente confirmación en las audiencias de la adhesión al modelo político y económico del país, ocultando sus fisuras; o bien minimizando sus más evidentes fracasos, como la masa de personas desplazadas por la exclusión hacia sus características sociales, raciales, extranjeras, o de diversidad sexual. Se trata de los restos que va dejando el capitalismo en sus bordes y que Diamela Eltit describe así:

grupos de oprimidos sociales que internalizan cada uno de los presupuestos excluyentes que emanan de las voces dominantes [...] hijos de la carencia [...] sujetos periféricos, despojados de recursos pensantes [...] Ellos se apropian de esas voces discriminatorias y las ejercen contra sus pares sociales y así reproducen, en sus espacios, una idéntica jerarquización a la que experimentan en sus transcursos de vida. ("Hagamos memoria")

Para la escritora, el discurso de exclusión es patrimonio de la derecha económica, aliada con el poder militar, jurídico y eclesiástico, y con la complicidad política de los centros y las izquierdas. Este poder concertado produce lineamientos que atentan contra la convivencia social y que se traducen en: "racismo, machismo, nacionalismo, homofobia, pechoñería". Tales modelos coercitivos fueron implantados en los imaginarios sociales de clases medias y populares, dando origen a un "fascismo popular" (Eltit, "Hagamos memoria"), que se aloja en sujetos cuyo único acceso al poder es la violencia con el otro distinto, como ocurrió con el joven homosexual Daniel Zamudio:

La infortunada muerte del joven Daniel Zamudio a manos de una serie de cretinos filonazis forma parte de lo previsible en los ejes sociales en los que habitamos. El circo mediático se apropió del cuerpo agónico del joven 
para establecer un superficial, incesante espectáculo macabro. Hasta allí llegaron los protagonistas de la coerción social: representantes de la UDI cuyo capital más fuerte de intransigencia se centra en la obsesión por los controles genitales. Acudió también el ministro del Interior, responsable por las feroces agresiones policiales a las legítimas protestas sociales y que en Aysén causaron diversas lesiones y la pérdida de visión en varios trabajadores. Y también hay que sumar la intervención insólita de la iglesia chilena, que es abiertamente homofóbica y que niega y reprime hasta la asfixia la existencia de un contingente significativo de sacerdotes homosexuales. ("Hagamos memoria")

En este análisis a la cobertura de la agresión a Zamudio, que Eltit califica de "circo mediático", realiza una nueva aproximación conceptual al campo semántico del periodismo tétrico, al asociarlo con el sintagma "espectáculo macabro", al que dota de una doble carga de sentido en la dimensión connotativa del lenguaje. Por una parte, este enunciado designa un evento mediático impropio en torno al cuerpo moribundo del joven, y por otra, refiere a la apropiación política del hecho por los mismos emisores de discursos disciplinarios anclados en la violencia y la represión.

La escritora también denunció un tipo de "cursilería intelectual", desde luego clasista, que otorga figuración pública preferente en el ámbito cultural a un sujeto letrado, como Miguel Serrano, dada su condición de escritor de clase alta. Asegura que ello genera confusión, cuando se omite su filiación nazi o se considera "un aspecto exótico e intrascendente en la vida de un poeta fundamental" ("Hagamos memoria"). Para Eltit, este personaje es un referente inspirador del "fascismo popular", y su influencia produce en los sectores periféricos y en una elite de izquierda aspiracional, "la parodia más kitsh del nazismo tercermundista" ("Miguel Serrano").

Los discursos sociales de exclusión son ubicuos en la desigualdad, mientras por una parte inhiben las libertades individuales, por otra, conceden toda "la 
libertad (del mundo) a la ganancia empresarial sin límites, entre ellas la educación y la salud [...]ganancias, generadas a costa del cuerpo más concreto de la población", ("Hagamos memoria"). Ello crea una distancia social entre los cuerpos segregados por el acceso al consumo y el anhelo de consumo penetra los imaginarios sociales, derivado de un neoliberalismo frenético "que terminó por igualar el valor del objeto con el sujeto" ("Bachelet Qué Pasa").

Precisamente, el caso Oporto es un paradigma de esa equivalencia de asignación de valor a objetos materiales, susceptibles de ser robados, con la vida humana del sujeto que roba. El error de esa ecuación arranca de la omisión de un factor determinante: la desigualdad estructural irrebatible que produce un crecimiento exponencial de la delincuencia.

Eltit denuncia que el vocablo desigualdad "ha perdido su dramatismo, para transformarse en una palabra técnica, retórica, sin cuerpo, sin territorios, sin habla" (Oliveros, "Diamela Eltit: La desigualdad") ${ }^{6}$. Más aún, la pensadora asegura que la desigualdad se ha fragmentado, hasta tal punto que existen los segregados "buenos" y los "malos". Estos últimos serían los delincuentes:

Entonces, esa desigualdad opera en su interior, en el sentido de que la desigualdad se fragmenta, sobre todo en los sectores populares, produciendo buenos segregados y malos segregados, o buenos desiguales y malos desiguales, fundamentalmente a través del tema de la delincuencia, delincuencia que ha existido siempre y seguirá existiendo. (Oliveros, "Diamela Eltit: La desigualdad")

\footnotetext{
${ }^{6}$ Este artículo de Tatiana Oliveros resume la ponencia presentada por Diamela Eltit en el panel "Desiguales, la importancia de tener una voz" en el Congreso Futuro de enero 2019.
} 


\section{Segundo momento: la tradición de la prensa liberal}

Las reflexiones de Diamela Eltit sobre el discurso ideológico del sistema de medios chilenos se inscriben en una tradición de estudios iniciada en nuestro país por Armand y Michèle Mattelart, y Mabel Piccini, en las décadas del 60 y 70; Fernando Reyes Matta, Carlos Ruiz, Fernando Ossandón ${ }^{7}$ y Guillermo Sunckel ${ }^{8}$, en 1986; Eduardo Santa Cruz, $1988^{9}$, Patricio Dooner, 1989¹0, Ángel Soto Gamboa, 1995; Ramos y Guzmán, 2000; y Lagos et al, 2009. Estas investigaciones abordan principalmente la prensa escrita, dado que, tradicionalmente, ha detentado hegemonía en las preferencias informativas políticas de los sectores que toman decisiones relevantes para el país.

De acuerdo con Santa Cruz (43-45), la concepción liberal moderna de la prensa como empresa periodística comienza en 1900 con la fundación de $E l$ Mercurio de Santiago. Surge entonces la "prensa empresa" definida por una pretensión informativa que tiende a generar un mercado noticioso competitivo y de innovación tecnológica. Con ello se consuma la libertad de prensa liberal en un momento histórico en que el pensamiento liberal ya no representa un factor de cambio social, sino de consolidación del sistema capitalista, y la prensa se constituye en su aparato ideológico: "La concepción de la prensa liberal moderna se impone [...] sobre la base de ocultar su verdadero carácter. Si se ha constituido como aparato ideológico del estado burgués, se presenta como "objetiva" y "neutral”, (Santa Cruz 47).

La tesis de Santa Cruz se inserta en el marco teórico iniciado por Mattelart y Piccini ("La prensa burguesa"), quienes detectaron que la prensa liberal chilena,

\footnotetext{
${ }^{7}$ Ossandón, Fernando: “El Mercurio y la represión, 1973 a 1978”, en Reyes Matta, Fernando, Ruiz, Carlos, Sunkel, Guillermo. La Investigación sobre la prensa en Chile (1974-1984).

${ }^{8}$ Sunkel, Guillermo: "El Mercurio como medio de educación político-ideológica (1969-1979)" en Reyes Matta, Fernando, Ruiz Carlos, Sunkel Guillermo: Investigación sobre la prensa en Chile (1974-1984).

${ }^{9}$ Eduardo Santa Cruz. Análisis histórico del periodismo chileno.

${ }^{10}$ Periodismo y Política. La prensa de derecha e izquierda 1970 - 1973.
} 
filiada a la derecha, había constituido "un frente de comunicaciones" como soporte de su lucha ideológica contra el gobierno de la Unidad Popular, apelando a los conceptos de libertad de expresión, objetividad y pluralismo. A juicio de las autoras, estas nociones no eran más que la expresión metafórica para encubrir sus intereses de clase y "camuflar la defensa de la libertad de propiedad privada en nombre de la cultura, del espíritu y de los grandes principios democráticos” (253).

Posteriormente, las investigaciones de Ossandón y Sunckel ratificaron que, particularmente en el periodo 1970-1973, la prensa escrita se convierte en un instrumento de acción política y en un vehículo de educación político-ideológica orientado primero, a la desestabilización del gobierno de Allende (Dooner) y, después, a consolidar, desde una matriz política neoconservadora, el proyecto neoliberal de reestructuración capitalista instaurado por la dictadura. Esta última idea es refrendada por Soto Gamboa, quien estudia la difusión doctrinaria del liberalismo económico en El Mercurio, fundamentado en la propiedad privada del capital; la legítima ganancia; el reconocimiento del interés personal, como motor principal e irremplazable de la actividad económica, y la preferencia de la libertad, como regla general, sobre el intervencionismo del Estado" (Soto Gamboa 17).

Más recientemente, el libro El diario de Agustín (Lagos et al) y el documental del mismo nombre de Ignacio Agüero, develaron la complicidad de $E l$ Mercurio con el terrorismo de Estado de la dictadura para encubrir las violaciones a los derechos humanos. Ser la voz oficial de la dictadura fue al mismo tiempo una oportunidad de negocios para aumentar la hegemonía periodística a costa de la clausura de los medios disidentes del golpe de Estado. Así lo confirma, Claudia Lagos:

La posición hegemónica del Mercurio tiene su explicación en parte en cómo se clausura el mercado de los medios después del golpe, con el cierre de muchos medios. Si en la mayoría de las regiones el único diario que 
hay es de la cadena El Mercurio. Si lo dice [Arturo] Fontaine ${ }^{11}$, que no vieron mal el que desapareciera la competencia después del golpe, no lo miraron con malos ojos pese a que su caballo de batalla contra Allende era la libertad de prensa. (El diario)

Según el marco conceptual de los estudios analizados, dada la condición mercantil en que opera la prensa liberal, bajo la apariencia de custodiar el interés nacional, defiende un estatuto ideológico, asociado a intereses de clase. Así, la libertad de expresión se reduce a cautelar la propiedad de los medios detentada por grupos monopolistas. En ese marco, la elite que domina la estructura de poder de la información requiere imponer su visión particular del mundo como una visión compartida por toda la sociedad; y eleva su verdad y sus intereses al rango de universalidad.

Ahora bien, para cursar la ideología en sus productos editoriales, la prensa liberal recurre a lo que el estudio de Mattelart, Mattelart y Piccini, describe como mecanismos reductores de la realidad que le permiten ajustar los hechos noticiosos a su escala de valores. Estos mecanismos se traducen en mitos y constituyen toda una mitología destinada a racionalizar y justificar su propio proyecto de sociedad. En este caso, la función del mito no es ocultar la realidad de un fenómeno, sino hacer desaparecer el sentido indicativo del problema social que lo origina; asignando al fenómeno explicaciones que esconden los cuellos de botella sociales y las contradicciones generales del sistema en que está inserto:

Como escribe Barthes, el mito vacía de lo real los fenómenos sociales, deja al sistema inocente: lo purifica. En cierto modo, priva a estos fenómenos de su sentido histórico y los integra a la "naturaleza de las cosas" [...] El mito, pues, domestica la realidad, la anexa en provecho de una pseudorealidad: la realidad impuesta por el sistema, la cual no es "real", sino

${ }^{11}$ Arturo Fontaine Aldunate, director de El Mercurio entre 1978 y 1982. 
admitiendo las bases sobre las cuales se halla edificada la ideología burguesa (la clase dominante como parámetro de objetividad y universalidad). (Mattelart, Mattelart y Piccini 25)

En los conflictos sociales por la ampliación de derechos ciudadanos, según los autores, la mitología presenta el orden social como un orden natural independiente de los intereses de clase; y promueve una noción de orden basada en un modelo autoritario de relaciones sociales, que desemboca en coerción y represión. En las protestas juveniles por la reforma universitaria de 1967, comprobaron que, si el joven obrero o el joven cesante ingresaban a la protesta, su intervención ya no se consideraba un hecho de rebelión juvenil, sino un hecho delictual. Asimismo, cuando la prensa liberal se veía confrontada al recurso de la violencia (tomas, ocupaciones ilegales) como medios de presión, sus argumentos lo atribuían a grupos extremistas que vulneran la institucionalidad.

En consecuencia, la cobertura de prensa de la protesta de 1967 se desarrolló en un circuito de lenguaje centrado en la isotopía representada por el binomio Violencia (terrorismo) versus Orden. Esta isotopía permite reabsorber la protesta en un marco delincuencial y apelar a la represión. La violencia es un significante irreductible para la prensa liberal, porque "es el único signo de la acción revolucionaria que $[\ldots]$ no puede recuperar $[\ldots]$ ya que constituye la negación de la institucionalidad" (Mattelart, Mattelart y Piccini 96-111).

Las instituciones encarnan el proyecto de sociedad de la prensa liberal y garantizan la estabilidad del sistema y la armonía en las relaciones sociales. Ambos factores son imprescindibles para la protección de sus intereses económicos. De ahí que la conflictividad, la violencia y la subversión, son amenazas inaceptables para el funcionamiento del orden social. En tales situaciones, la prensa liberal recurre a estrategias lingüísticas que le permiten desactivar la movilización social anulando 
su sentido. El semiólogo Eliseo Verón ${ }^{12}$ determinó que los titulares de prensa utilizan marcadores lingüísticos destinados a despojar de sentido a los acontecimientos de violencia política. La categoría "terrorismo", según Verón, es un operador lingüístico clave para semantizar la violencia de masas como un acto sin objeto. En Chile, desde 2000, la categoría "encapuchados" se ha tornado en un operador lingüístico que condensa y resignifica términos como violencia, terrorismo y delincuencia.

Las demandas por transformaciones estructurales de la sociedad han sido objeto de estrategias mediáticas basadas en el miedo, la amenaza política y las "campañas del terror", desde la primera mitad del del siglo XX. La psicóloga Elisabeth Lira Kornfeld, quien ha estudiado el miedo como instrumento de control de la conducta colectiva en Chile asegura que, si bien alcanzó su clímax en la dictadura militar, ha sido utilizado en periodos previos y posteriores al golpe de Estado. Una forma de propaganda orientada a crear una subjetividad colectiva en "estado de amenaza", se ejerció contra la elección presidencial de Pedro Aguirre Cerda en 1938. El candidato representaba un riesgo para los intereses económicos de la derecha y el conservadurismo católico y se le asoció con la pérdida de libertad religiosa y la guerra civil española. También las sucesivas campañas presidenciales de Salvador Allende fueron objeto de discursos mediáticos de terror que lo vinculaban con el comunismo y la dictadura del proletariado. Esto significó una exposición masiva y prolongada de todos los chilenos a las consecuencias fatales que tendría para su vida personal, familiar y social, y para sus creencias religiosas el advenimiento de un gobierno socialista. Esta propaganda, según Lira Kornfeld, se basó en un supuesto simple que asociaba el orden establecido con la nación, como entidad inmutable, por lo tanto, todo cambio se constituía en amenazante. Asimismo, en la franja televisiva previa al plebiscito de 1988, la opción SI, centró su campaña en el peligro y los riesgos que acarrearía a la sociedad chilena que Pinochet dejara de gobernar, vinculando reiterativamente la violencia extremista

${ }^{12}$ Eliseo Verón: "Ideología y comunicación de masas: la semantización de la violencia política". Lenguaje y comunicación social. 
con la amenaza a la vida y a la pérdida de los medios y las formas de vida (Lira Kornfeld).

A juicio de Lira Kornfeld, las campañas del terror generalizan al conjunto de la sociedad lo que representa una amenaza para los intereses de un sector de ella. No obstante, con el bombardeo permanente de noticias de contenido amenazante se generaliza un clima de temor y ansiedad. Esta atmósfera destruye las relaciones sociales instalándolas en la lógica amigos-enemigos, que tiene efectos devastadores en la convivencia social. La construcción psicológica e ideológica de la categoría de enemigo contiene un elemento "siniestro y aterrador", porque se trata de una violencia estructural interiorizada en la cual se olvida que "el otro", enemigo, es también un ser humano. La consecuencia psicosocial es muy drástica: la devaluación de la vida humana (Lira 27-38).

El rol de los medios de comunicación en la producción de percepciones de riesgo para el consumo de las masas fue indagado por Ulrich Beck, quien vincula la sensación de riesgo con la necesidad de consumo, dada la brecha existente entre los diferentes grupos sociales. La lógica de apropiación capitalista y el consumo excesivo no sustentable configuran una sociedad del riesgo que produce un clima de inseguridad creciente, donde la seguridad se convierte en un bien escaso. Por un lado, aparece el riesgo como oportunidad de mercado que incentiva la explotación comercial de mecanismos de seguridad; y por otro, la sensación de inseguridad y de riesgo trastorna en la ciudadanía las relaciones comunitarias. La idea de reciprocidad y participación comunitaria se reemplaza por el anhelo de protección, dando origen a la "comunidad del miedo", en la que la solidaridad surge por miedo y se convierte en una fuerza política (Bell, Korstanje).

En el campo de los estudios literarios, Jean Franco subraya que una cultura del miedo caracteriza la modernidad tardía en América Latina, donde existen zonas geográficas en que los habitantes viven dominados por mini totalitarismos, un término con que la autora designa el control de la vida cotidiana de la población a través del miedo; "miedos acechantes que dan forma a nuestro presente y nuestro futuro" (41-42). 
La construcción social del miedo, como herramienta de control, se va actualizando de acuerdo los requerimientos del capital en el sistema político. En Chile, al inicio de la transición a la democracia, en 1990, hubo una transformación estructural en la estrategia del miedo Precisamente, cuando el advenimiento de un gobierno democrático debía difuminar el temor a la represión política, emergió un nuevo pánico en la población: El terror a ser víctima de la delincuencia, debido a la percepción generalizada de que ésta había sobrepasado los límites de la tolerancia y se hallaba en completo descontrol. Pese a que las estadísticas de criminalidad indicaban lo contrario, la delincuencia y la seguridad ciudadana se convirtieron en el tema de mayor prioridad en la agenda pública de la postdictadura chilena.

La emergencia de este discurso ideológico, con fuerte presencia en el conjunto de medios de comunicación, fue abordado por los periodistas Marcela Ramos y Juan Andrés Guzmán, quienes aseguran que, en el Chile de la transición, "el delito deja de ser una suma de infracciones a la ley para convertirse en una forma de ver y construir la realidad" (Ramos y Guzmán 35).

Ramos y Guzmán propusieron entender esta problemática "como un corpus doctrinario" de polarización social (Campos Álvarez 125), intensificado por la Fundación Paz Ciudadana, creada por el propietario de El Mercurio, cuya influencia se expande a la clase política de centro e izquierda, así como al sistema de medios en su conjunto. Según los autores, este discurso ideológico mediático generó un enorme negocio de control del delito y estimuló la criminalización de la pobreza, estigmatizando a los jóvenes y pobladores de los barrios marginales de Chile.

De este modo, los ladrones profesionales y aficionados se convirtieron en el enemigo más odiado de la ciudadanía. Ladrones, cada vez más jóvenes, quienes, según la socióloga Doris Cooper, provienen de los estratos sociales más desposeídos de la sociedad y que se caracterizan por su aspecto indígena: 
En su mayoría han sido niños/as abandonados por sus padres o que han escapado para evitar la violencia doméstica y la violación incestuosa dentro de la familia. Se crían en las calles uniéndose a pandillas de muchachos ladrones más experimentados. Algunos son internados en orfelinatos estatales o privados donde crecen formando grupos de ladrones con conciencia generacional. (Vidal 118)

En la perspectiva del periodista uruguayo, Carlos Fazio, la construcción social del miedo en México ha sido una estrategia de manipulación mediática para apoyar controvertidas decisiones del poder político y económico, en el periodo 2006 a 2011. Fazio destaca el rol fundamental del monopolio mediático Televisa, que, a su juicio, ha ejercido una dictadura, y un "golpismo" mediático, guiado por el rating y el poder del dinero. La tesis de Fazio es que en México permeó el discurso de la guerra contra el terrorismo de Estados Unidos, que generó un periodismo del miedo para afianzar la entrega de poderes especiales al Estado. Asegura que, con ese mismo discurso en México, el presidente Peña Nieto, declaró la guerra contra el narcotráfico, provocando la militarización del país que exacerbó los crímenes y la violencia. Las políticas de seguridad interna y antiterroristas, permitieron al gobierno un mayor control sobre la población y sobre sus opositores políticos. El servilismo de los medios ante esas políticas se expresó en estrategias de propaganda, censura, guerra psicológica, y espectacularización, configurando prácticas de "Terrorismo mediático":

Tanto en el caso de Estados Unidos como en el de México, los medios cumplieron un papel de difusores del miedo, esparciendo noticias sobre posibles ataques que por algún tiempo generaron un ambiente de sicosis en la población, manipulando las noticias en función de objetivos que buscaban afianzar posiciones de poder en la sociedad. (Castillo 94) 


\section{Tercer momento: definición de periodismo tétrico}

Sobre la base de las huellas del proceso de producción del discurso ideológico de la prensa liberal chilena, fue posible rastrear las capas de sentido sedimentadas a través de un siglo de prácticas constituyentes de ideologemas, que articulan los mensajes periodísticos en función del libre mercado liberal y neoliberal.

El repertorio de ideologemas ha sido permanente actualizado, reciclado y recodificado para adaptarse a las nuevas tecnologías de las plataformas comunicacionales en la globalización. Sin embargo, este remozamiento no implicó una renuncia, sino una revitalización de la explotación de la noticia como mercancía. Así se confirmó el pronóstico de Guy Debord en 1967 sobre la última forma del capitalismo:

se anuncia como una inmensa acumulación de espectáculos en los que todo lo que se vivía directamente se ha ido alejando y se ha convertido en una representación [...] el espectáculo es el capital a un grado de acumulación tal que deviene en imagen. (3)

Precisamente, en el mundo organizado por los medios de comunicación, el Estado y la economía mercantil adquieren una soberanía absoluta. Y esa soberanía no puede ser conservada sin la amenaza permanente a la seguridad construida sobre una desigualdad obscena, amenaza que se asigna por sinécdoque la ciudadanía toda. Por ello, la voluntad de polarización aparece como una constante en la historicidad del flujo del discurso del poder.

Desde el Análisis Crítico del Discurso, Teun Van Dijk, define la polarización como una jerarquización de las relaciones sociales entre un grupo que detenta una posición de mayor poder y control discursivo sobre los "otros", determinados por figuras opuestas como "superiores/subordinados; elites/masas; mayorías/minorías" (Ideología 205-206). 
La dominación discursiva se ejerce a través de diversos mecanismos que modifican las relaciones entre proposiciones mediante predicados y argumentos que cumplen funciones de agentes, pacientes y beneficiarios. Por ejemplo, la presentación de los "otros" como agentes de acciones negativas y de amenaza, mientras el grupo de poder es el que recibe pasivamente la amenaza (Van Dijk "Discurso y dominación"). La lexicación del discurso en la polarización opera con la selección de palabras que enfatizan la negatividad de los "otros". El signo "encapuchados", por ejemplo, es una actualización léxica de significantes anteriores como violentistas, terroristas, extremistas.

También hay otros dispositivos sintácticos como el uso de las oraciones pasivas y las nominalizaciones para esconder o minimizar la agencia en situaciones negativas para los grupos de poder. Por ejemplo, el enunciado: "Se produjo un enfrentamiento a tiros", enmascara los disparos de la policía contra civiles desarmados. Así, los titulares de prensa, denominados "superestructuras", organizan el significado global con enunciados de fácil ingreso a la memoria colectiva, por lo tanto, penetran los modelos mentales de los receptores del mensaje comunicativo ("Discurso y dominación").

Todos estos mecanismos estudiados en las formalidades discurso, en la superficie misma del lenguaje, por sutiles que parezcan, cumplen la misma función que las estrategias de violencia simbólica, los efectos de realidad, el uso de operadores lingüísticos marcados, las isotopías binarias, la mitología y las campañas del terror. Configuran el metalenguaje comunicativo del control político y social en las sociedades contemporáneas de la información y la comunicación.

Por eso, la noción de "periodismo tétrico", formulada por Diamela Eltit, nos invita a pensar cómo opera el poder en todas sus dimensiones y las dinámicas que lo materializan en subjetividades colectivas subordinadas por la extorsión de la amenaza a la estabilidad y gobernabilidad de la nación, concebida como entidad inmutable al servicio del mercado.

La desigualdad fragmentada referida por Eltit es la segregación del "lumperío", de "los desarrapados" y "los pálidos", aquellos desplazados a los 
bordes y a la marginalidad, los ambulantes que pugnan por sobrevivir en las calles apropiadas por un mercado que los expulsa; los adolescentes tránsfugas de los semilleros del delito, que son los hogares de menores en riesgo social, descartados por una sociedad que los excluye o los arroja al destino de mano de obra barata.

De acuerdo con las reflexiones de Diamela Eltit, el concepto de periodismo tétrico sería entonces una representación en clave espectacular de un evento noticioso, a través de signos sobresaturados que anulan la complejidad inmanente del suceso, traicionando su sentido al opacar lo ominoso del contexto en que emerge el evento comunicado. En esa línea, es un tipo de narrativa ideológicamente controlada, que visibiliza una porción incompleta de la realidad o solo "efectos de realidad", vaciados de sentido mediante dispositivos reductores de los significados sociales y contextuales del suceso noticiado.

En síntesis, el periodismo tétrico provoca lo que Nelly Richard, designa como una "desconexión sintáctica" (89) entre el sujeto de la noticia, el contexto que la envuelve y el predicado que la nomina, convirtiéndola en una representación de óptica engañosa.

El componente siniestro, macabro o tétrico estaría dado por una espectacularización de la muerte, con una doble carga semántica. Por un lado, como castigo legal de los sujetos que quiebran el contrato social normativo, sin cuestionar la legitimidad de ese convenio pactado por el mercado y el capital; y por otro, también aloja una pulsión criminal derivada de la fragmentación de la desigualdad con una lógica binaria: buenos/malos; amigos/enemigos; hombres/mujeres; blancos/indígenas. Para ello, presenta el orden institucional como un "orden natural", independiente de los intereses de clase, género y etnia que lo atraviesan. Así estimula el clasismo, el racismo, el machismo, el nacionalismo, la homofobia y la pechoñería, sostenidos como discurso oficial por una concertación del poder político, militar, jurídico, eclesiástico y empresarial- que marca los modelos mentales de la población.

Al reproducir en forma acrítica el discurso dominante, anclado en la criminalización de la diferencia y la otredad, se hace cómplice de los 
procedimientos de sumisión (Foucault) para subordinar los imaginarios sociales a una devaluación de la vida humana, al hacer equivalente el valor del sujeto con el valor del objeto de consumo.

El concepto de periodismo tétrico también implica una reflexión sobre la ética y la responsabilidad en las prácticas de construcción de la noticia. Particularmente, en la prensa televisiva cuando la selección de contenidos está externalizada en empresas productoras que escogen los entrevistados, elaboran el guion de las preguntas y determinan el tono, el ritmo y el control del tiempo en el programa. En el caso de "Aquí está Chile", la encargada de las disculpas públicas por la falsedad del caso Oporto, fue la productora, exculpando de responsabilidad a los periodistas. No obstante ¿puede el periodista escudarse en haber seguido al pie de la letra un guion externo, sin haberlo cuestionado, desligándose de toda responsabilidad en los efectos que causó?

En el periodismo tétrico la relación periodista/entrevistado se desenvuelve en una dinámica de jerarquía superior/inferior. Diamela Eltit, la metaforizó como "un teatro de las humillaciones". La misma distribución circular de la escena periodística, ubicando al entrevistado al centro de las graderías, se asocia a la expectación en un coliseo. Al mismo tiempo, las preguntas de los periodistas van incrementando la tensión dramática, como si fuese el temible interrogatorio penal en un juicio público. En ese escenario, el periodista detenta la jerarquía investido de una "superioridad moral", cuestionada por Eltit, como un tipo de violencia simbólica que tiende a "desnudar" los errores, contradicciones y aspectos polémicos del entrevistado.

No hay en toda esta situación, ni más ni menos, que lo códigos de espectacularización del género infoentrenimiento. La tensión dramática está intensificada también con recursos técnicos: efectos de sonido, efectos de cámara, que aceleran el ritmo en la secuencia de imágenes (Berrocal et al 66). Hasta el protagonismo del periodista es una estrategia de la telerrealidad que lo construye como la estrella del show, quien encarna una serie de cualidades: liderazgo, verosimilitud, credibilidad, que forman parte del marketing comercial y editorial 
de la cadena televisiva. El telespectador empatiza con este rostro familiar que ya es parte de su vida cotidiana y acepta sus proposiciones como un régimen de verdad. Sin embargo, la impostura ideológica del periodismo tétrico queda al descubierto cuando se inhibe de desvestir la violencia del discurso oficial hacia los sujetos transgresores, estigmatizados por el orden dominante. En este caso, el "periodismo tétrico" auxilia la reproducción de la desigualdad.

Finalmente, así como el periodismo tétrico emerge en el discurso, el umbral de salida para este esquema de abuso de poder se encuentra también en el orden del discurso. Como remarca Van Dijk, la dominación se contrarresta con la vigilancia sobre los enunciados normativos, litigando con sus representaciones hegemónicas. Fiscalizando que el discurso regulador se mantenga en un marco de respeto a los principios de emancipación y equilibrio de poderes entre el Estado y la sociedad civil. Democratizando el poder mismo al redistribuirlo en el conjunto de la sociedad.

\section{Reflexiones finales}

Las huellas del pasado nos conducen a la verificación de que muchos de los problemas ideológicos planteados en los estudios de la prensa liberal desde la década del sesenta, continúan vigentes, o se han agudizado. Por ello, el concepto de periodismo tétrico, acuñado por Diamela Eltit, permite abarcar el conjunto de prácticas comunicativas con que el discurso liberal y neoliberal se inocula en la memoria y la racionalidad colectiva; naturalizándose en los modelos mentales hasta constituirse en un imaginario social dominante en las clases medias y en los sectores populares.

En esa operación, la cultura mediática es un soporte fundamental para producir una subjetividad colectiva en estado permanente de amenaza, que beneficia la expansión del capital. Las extorsiones de sentido de la prensa liberal tienen una historicidad previa y posterior a la dictadura. 
El periodismo tétrico analizado en este artículo, al anteponer la emoción y el impacto, al rigor informativo se inscribe en un sensacionalismo equivalente al antiguo formato tabloide de la prensa escrita. También presenta elementos que lo aproximan peligrosamente a la frontera del terror. Sobre todo, si se piensa en la complicidad de los medios con la guerra sucia del terrorismo de Estado de la dictadura. Pero la noción de periodismo tétrico aquí trabajada no abarca el significado de terrorismo mediático descrito por Fazio, ya que éste incluye periodistas sicarios, conectados al narcotráfico y gobernados por los códigos criminales de las mafias. En Chile no hay evidencias de que se halla cruzado ese umbral, por ahora.

\section{Bibliografía}

Beck, Ulrich. La sociedad del riesgo. Hacia una nueva modernidad.

Barcelona/Buenos Aires: Paidós Ibérica, 1998 [1986].

Berrocal, Salomé, Marta Redondo y Eva Campos. "Una aproximación al estudio del infoentretenimiento en Internet: origen, desarrollo y perspectivas futuras". adComunica. Revista Científica de Estrategias, Tendencias e Innovación en Comunicación 4 (2012): 63-79.

Bourdieu, Pierre. Sobre la Televisión. Barcelona: Anagrama, 1997.

Cáceres, María Dolores. "El discurso de la televisión en la cultura del espectáculo: los procesos de mediación en los programas de la telerrealidad”. Sphera Pública 10 (2010): 207-222. 
Campos Álvarez, Diego. "Reseña de 'La Guerra y la Paz Ciudadana, de Marcela Ramos y Juan Andrés Guzmán"”. EURE (En línea] Vol. XXVII.82 (2001).

Castillo, Anabel. "Terrorismo Mediático: la construcción social del miedo en México. Carlos Fazio (2013) ISBN: 978-607-311-410-3 429 páginas". Chasqui. Revista Latinoamericana de Comunicación 125 (2014): 93-95.

Dooner, Patricio. Periodismo y Política. La prensa de derecha e izquierda 1970 1973. Santiago: Editorial Andante, 1989.

El diario de Agustín. Dir. Ignacio Agüero. Amazonia films/Ignacio Agüero \& Asociado. 2008. Documental.

Eltit, Diamela. "Aquí está Chile y Pablo Oporto: Espectáculo periodístico tétrico". 12 de junio de 2017. El desconcierto.cl. Web. 13 de marzo de 2019. . "Arrate en el debate: Pero se mueve". 10 de octubre de 2009. The clinic.cl. Web. 25 de abril de 2019.

. "Bachelet, Qué Pasa y el 'caso' del matrimonio Dávalos-Compagnon: Hacer noticia”. 10 de junio de 2016. El desconcierto.cl Web. 8 de febrero de 2019.

. "Hagamos memoria: cretinos filonazis". 10 de abril de 2012. The clinic.cl. Web. 26 de abril de 2019. . "La memoria pantalla (Acerca de las imágenes públicas como política de desmemoria)". Revista de Crítica Cultural 32 (2005). . "Miguel Serrano, la parodia más kitsh del nazismo tercermundista. Literatura y nazismo". The Clinic 293 (2009).

Enaudeau, Corinne. Las paradojas de la representación. Buenos Aires: Paidós, 2006.

Errazuriz, Pilar. "El Rostro Siniestro de lo Familiar: Memoria y Olvido". cyberhumanitatis.uchile.cl 19 (invierno 2001). Web. 26 de abril de 2019.

Fazio, Carlos. Terrorismo mediático. La construcción social del miedo en México. México: Debate, 2013. 
CATEDRAL Tomada: Revista de crítica literaria latinoamericana / Journal of Latin American Literary Criticism

Diamela Eltit: la noción de periodismo tétrico, ideología y discurso en la prensa (neo)liberal chilena

Fluxa, Rodrigo y Arturo Galarce. "El justiciero imaginario”. Sábado/El Mercurio (2017).

Foucault, Michel. El orden del discurso. Trad. Alberto González Troyano.

Buenos Aires: Tusquets, 1992 [1970].

Franco, Jean. Una modernidad cruel. Ciudad de México: Fondo de Cultura Económica, 2016.

Freud, Sigmund. "Lo ominoso". Obras Completas Vol. XVII. Ed. J. Strachey.

Trad. J.L. Echeverry y L. Wolfson. Buenos Aires: Amorrortu, 1993 [1919].

Korstanje, Maximiliano. "Reseña de 'La sociedad del riesgo: hacia una nueva modernidad' de Beck, Ulrich”. Economía, Sociedad y Territorio Vol. X.32 (2010): 275-281.

Lagos, Claudia (ed), y otros. El diario de Agustín. Cinco estudios de casos sobre El Mercurio y los derechos humanos (1973-1990). Santiago: ICEI/Lom, 2009.

Lira, Elisabeth. "Psicología de la amenaza política y el miedo (manuscrito)". 1991 Web. www.psicosocial.net. Web. 21 de abril de 2019.

Mattelart, Armand, Michèle Mattelart y Mabel Piccini. Los medios de comunicación de masas. La ideología de la prensa liberal en Chile. Buenos Aires: Shapire Editor/El Cid Editor, 1976 [1970].

Mattelart, Michèle y Mabel Piccini. "La prensa burguesa ¿no será más que un tigre de papel?” Cuadernos de la realidad nacional 16 (1973): 250-262.

Morales, María Cristina. “Análisis de un producto de infoentretenimiento. Estudio de la octava temporada del programa Salvados”. Periodismo Universitat Jaume I. 2014.

Oliveros, Tatiana. "Diamela Eltit: 'Desigualdad se ha transformado en una palabra técnica, sin cuerpo'". 22 de febrero de 2019. El mostrador.cl. Web. 6 de marzo de 2019.

“Ossandón por La Araucanía: Hay que meter balas al que sea terrorista”. 4 de junio de 2017. cooperativa.cl Web. 30 de marzo de 2019. 
Ossandón, Fernando. “El Mercurio y la represión, 1973 a 1978”. Reyes Matta, Fernando, Carlos Ruiz y Guillermo Sunkel. La Investigación sobre la prensa en Chile (1974-1984). Santiago: CERC/ILET, 1986.

Ramos, Marcela y Juan Andrés Guzmán. La Guerra y la Paz Ciudadana. Santiago: Lom, 2000.

Reyes Matta, Fernando, Carlos Ruiz y Guillermo Sunckel. La Investigación sobre la prensa en Chile (1974-1984). Santiago: CERC/ILET, 1986.

Richard, Nelly. Feminismo, género y diferencias(s). Santiago: Palinodia, 2008.

Santa Cruz, Eduardo. Análisis histórico del periodismo chileno. Santiago: Nuestra América, 1988.

Soler, María y Javier Marzal. "La emergencia del infoentretenimiento en España: la visión de editores y productores de informativos en televisión". Casero, Andreu y Javier Marzal. Periodismo en televisión: nuevos horizontes, nuevas tendencias. Sevilla/Zamora: Comunicación Social. Ediciones y publicaciones, 2011. 84-103.

Soto Gamboa, Ángel. El Mercurio y la difusión del pensamiento politicoeconómico liberal 1955-1970. Santiago: Instituto Libertad, 1995.

Stern, Steve J. "De la memoria suelta a la memoria emblemática: Hacia el recordar y el olvidar como proceso histórico (Chile, 1973-1998)". Jelin, Elisabeth. Memorias de la represión Vol. 3. Las conmemoraciones: Las disputas en las fechas "in-felices". Madrid: Siglo XXI Editores, 2002. 11-33.

Sunkel, Guillermo. "El Mercurio como medio de educación político-ideológica (1969-1979)". Reyes Matta, Fernando, Carlos Ruiz y Guillermo Sunkel. Investigación sobre la prensa en Chile (1974-1984). Santiago: CERC/ILET, 1986.

Van Dijk, Teun. "Discurso y dominación. 25 años de Análisis Crítico del Discurso". Grandes Conferencias en la Facultad de Ciencias Humanas. Bogotá: Universidad Nacional de Colombia, 2004. 5-28. 
CATEDRAL TOMADA: Revista de crítica literaria latinoamericana / Journal of Latin American Literary Criticism Diamela Eltit: la noción de periodismo tétrico, ideología y discurso en la prensa (neo)liberal chilena

. Ideología. Una aproximación multidisciplinaria. Barcelona: Gedisa, 1999.

Verón, Eliseo. "Ideología y comunicación de masas: la semantización de la violencia política". Verón, Eliseo (ed), y otros. Lenguaje y comunicación social. Buenos Aires: Ediciones Nueva Visión, 1971. 133-191.

Vidal, Hernán. Chile: Poética de la tortura política. Santiago: Mosquito editores, 2000.

Walder, Paul. "El periodismo tétrico de Tolerancia 0". 26 de septiembre de 2017. El ciudadano.cl Web. 25 de marzo de 2019. 